\title{
A Comparative Study between Day Care and Routine Care Inguinal Hernia Mesh Repair
}

\author{
Ashwani Kumar ${ }^{1}$, Devadatta Poddar ${ }^{2}$, C Raja Bhanu Kiran ${ }^{3}$, Rohit Chauhan ${ }^{4}$ \\ ${ }^{1,4}$ Post Graduate Resident, ${ }^{2}$ Associate Professor, ${ }^{3}$ Registrar, \\ Dept of General Surgery, ABVIMS \& Dr RML Hospital, New Delhi.
}

Corresponding Author: Devadatta Poddar

\begin{abstract}
Inguinal hernia is one of the oldest diseases known to mankind. If not treated on time, patient may land up with complications. The basic principle of hernia surgery is tension free repair. There are no guidelines regarding an ideal surgery or anaesthesia to be used for inguinal hernia repair. Around $10-12 \%$ patient visiting outpatient clinic suffer from inguinal hernia and occupy a significant space in the operative list. Day care surgery in which the patient is discharged within 24 hours of surgery is gradually becoming the norm. A lot of centres are performing exclusive day care surgery with a good patient acceptance, thus reducing the burden on the hospital.

In this study conducted on 68 patients in a public tertiary care centre, we have compared day care versus routine care inguinal hernia surgery with 34 patients in each group. Lichtenstein hernia repair was done for all patients. The procedure was done under local anaesthesia for the day care surgery group whereas local/spinal/general anaesthesia was used for routine care group. Patients were admitted and discharged on the same day in day care group while patients in routine care group were admitted and discharged as per and norms of in-patient care. The feasibility of the procedure, recovery time, readmission for surgery related complications, and patient satisfaction was compared among the two groups.

We concluded that day care surgery is a feasible option, with early recovery, short stay, early ambulation, minimal complications, and significant patient satisfaction. Day care procedures have an edge over routine care public tertiary care hospitals.
\end{abstract}

Keywords: Inguinal hernia, day care surgery, Lichtenstein repair.

\section{INTRODUCTION}

Inguinal hernia is known to mankind since ancient Egypt with written description available since $1550 \mathrm{BC}$ as per National Institute of Health (NIH). An approximately $10-12 \%$ present with inguinal hernia of all patients attending the outpatient clinic.

There is no medical treatment for inguinal hernia and thus surgical correction is the only option. The first hernia surgery was done by Edoardo Bassini in 1880s. Since then various techniques have been described and there has been a paradigm shift in the treatment of inguinal hernia. [2] The principle of good repair is that the repair should be free of tension over tissues. However there are no guidelines currently for the type of surgery to be performed or the type of anaesthesia to be given for surgery. Lichtenstein repair can be performed under local anaesthesia and has minimal recurrence $(<1 \%)$. Many centres across the world perform this procedure under local anaesthesia. ${ }^{[3]}$ The Shouldice Institute and Toronto Clinic use local anaesthesia in $100 \%$ of their cases. ${ }^{[1]}$ However, a lot of centres prefer general or regional anaesthesia for the same. Patients with inguinal hernia occupy a big chunk of the operating room list and consume a significant amount of time which can be devoted for other major surgeries.

Day care surgery in which the patient is admitted and discharged on the 
same day is now gradually becoming the trend across many parts of the world. Even in our country there are many centres which perform day care surgery. Day care surgery was first performed by Eric Furquharson in 1951 with the aim to reduce the number of waitlisted surgical patients in NIH. By definition, day care surgery is a planned procedure on patients who are admitted and discharged home on the day of their surgery but who require some time for recovery. In most countries the patient is discharged by evening however in some countries like the USA patient may spend less than 24 hours in the hospital. ${ }^{[4]}$ Careful selection of the patient, literacy level of the patient, type of anaesthesia, patients' residence from the hospital, and availability of a surgical team on telephone for consultation are some of the factors to be kept in mind before taking up the case for day care surgery. There are a lot of benefits of day care surgery especially when it comes to hernia surgery. It can be performed under local anaesthesia with a short hospital stay and quick recovery attributed to less post op nausea and vomiting (PONV), less blood loss, and comfortable environment at home. The patient can also work from home which is the latest trend in world hit by the pandemic.

In contrast, traditional or routine care surgery involves the patient to be admitted either on the day of surgery or a day prior to the surgery. The patient is operated under local/spinal/general anaesthesia and sent home after suture removal. This consumes a lot of the hospitals workforce and beds thus incurring costs to the hospital and prolonging the waiting time for many patients requiring major surgery.

Discharge in day care surgery is planned when the patient is awake, has acceptable level of pain, no PONV, has passed urine and able to walk. A score of 9 and above in the Aldrete score was used as a criteria for discharge in this study. ${ }^{[5]}$

\section{MATERIAL AND METHODS}

This is a Prospective observational comparative study carried out at the General Surgery department of ABVIMS \& Dr. R.M.L. Hospital, New Delhi between November 2018 and March 2020. The sample size was calculated using the GPower 3.1 software. 68 patients were included in the study with 34 patients in each day care surgery and routine care surgery group. Patients presenting to the outpatient clinic and satisfying the inclusion and exclusion criteria were chosen. All the patients were counseled thoroughly about the day care and routine care surgery and the pros and cons of both procedures were explained. Consent for the procedure and participation in the study were obtained from all the patients. All the day care patients underwent Lichtenstein tension free hernia repair under local anesthesia whereas routine care patients underwent the same procedure in local/spinal/general anesthesia.

Statistical Analysis: The quantitative variables were expressed as mean $\pm \mathrm{SD}$ and compared between groups using unpaired $\mathrm{T}$ test. Qualitative variables were compared using chi-square/Fisher's exact test. A p value of $<0.05$ was considered statistically significant. The data was stored in Microsoft Excel spreadsheet and statistical analysis performed using IBM SPSS version 20.0 .

All patients in the age group 18-60 years presenting with uncomplicated inguinal hernia were included in the study. Patients with recurrent inguinal hernia or obstructed/strangulated/irreducible hernia were excluded from the study. The aim of the study was to look for the feasibility of day care surgery in a public tertiary care centre. Patient acceptance of the procedure, early ambulation, and post-op complications in the form of readmission for seroma/ infection was the secondary outcomes.

It was desirable that all day care patients were literate and had a literate attendant with them. They should be residing within a ten kilometer radius and 
have a suitable means of communication with the hospital. All day care patients were discharged on the same day. The Aldrete criteria as shown in table 1 was used for discharge and a patient with a score of $\geq 9$ was considered fit for return to home. ${ }^{[5]}$ All necessary instructions were provided on the discharge paper along with two contact number of the surgical team in case the patient needed to communicate with the doctor. Routine care patients were admitted in the ward on the day of surgery or on a day prior to the surgery. After the surgery the patient was shifted back to the ward for recovery and monitoring. Single dose of third generation cephalosporin after sensitivity testing was given to patients of both group pre and post-surgery. Single dose of injectable analgesic was given to patients of both groups in recovery.

Table 1: Aldrete score used for discharge of day care surgery group ${ }^{[5]}$

\begin{tabular}{|l|l|l|l|l|l|}
\hline SCORE & ACTIVITY & RESPIRATION & CIRCULATION & CONSCIOUSNESS & $\begin{array}{l}\text { OXYGEN } \\
\text { SATURATION }\end{array}$ \\
\hline 2 & $\begin{array}{l}\text { Moves all extremities } \\
\text { voluntarily/on } \\
\text { command }\end{array}$ & $\begin{array}{l}\text { Breathes deeply and } \\
\text { coughs freely }\end{array}$ & $\begin{array}{l}\text { BP +20 mm of pre } \\
\text { anaesthetic level }\end{array}$ & Fully awake \\
\hline 1 & Moves 2 extremities & $\begin{array}{l}\text { Dyspnoeic, shallow or } \\
\text { limited breathing }\end{array}$ & $\begin{array}{l}\text { BP +20-50 mm of pre } \\
\text { anaesthetic level }\end{array}$ & Arousal on calling & $\begin{array}{l}\text { Supplemental } \\
\text { required to maintain Spo2 } \\
>90 \%\end{array}$ \\
\hline 0 & $\begin{array}{l}\text { Unable to } \\
\text { move extremities }\end{array}$ & Apnoeic & $\begin{array}{l}\text { BP +50 mm of pre } \\
\text { anaesthetic level }\end{array}$ & Not responsive & $\begin{array}{l}\text { Spo2 }<92 \% \text { with oxygen } \\
\text { supplementation }\end{array}$ \\
\hline
\end{tabular}

First wound inspection was done on $3^{\text {rd }}$ post-op day (POD) and thereafter on the $7^{\text {th }}$ POD. If seroma or infection is noted then patient was reviewed in between. Long term follow-up to look for recurrence was not included in the study. All the patients in day care surgery group were also asked two questions. First, if they develop hernia on the other side will they like to get operated as day care or not. Second, will they suggest day care surgery for hernia to their relatives or friends. Their response was noted in the proforma.

\section{RESULTS}

The study population was divided into two groups in which day care surgery
(Group A) and routine surgery (Group B) was done.

Patients of the age group 18 to 60 years were included in the study. The youngest patient was of age 20 years and the eldest patient was of the age 59 years. The mean age in the day care group was 35.85 $( \pm 12.06)$ years and in the routine care group was $51.18( \pm 6.69)$ years.

Table 2: Distribution of patients according to the age in the 2 groups

\begin{tabular}{|l|l|l|l|l|}
\hline \multirow{2}{*}{ Age (years) } & \multicolumn{2}{|c|}{ Day Care Surgery } & \multicolumn{2}{c|}{ Routine Care Surgery } \\
\cline { 2 - 5 } & n & $\%$ & $n$ & $0.00 \%$ \\
$\leq 20$ & 3 & $8.82 \%$ & 0 & $0.00 \%$ \\
$21-30$ & 13 & $38.24 \%$ & 0 & $11.76 \%$ \\
$31-40$ & 4 & $11.76 \%$ & 4 & $20.59 \%$ \\
$41-50$ & 10 & $29.41 \%$ & 7 & $67.65 \%$ \\
$51-60$ & 4 & $11.76 \%$ & 23 & $100 \%$ \\
\hline TOTAL & 34 & $100 \%$ & 34 & \pm 6.69 \\
\hline Mean \pm SD & 35.85 & \pm 12.06 & 51.18 \\
\hline p-value & $<0.001$ & \multicolumn{4}{|l}{} \\
\hline
\end{tabular}

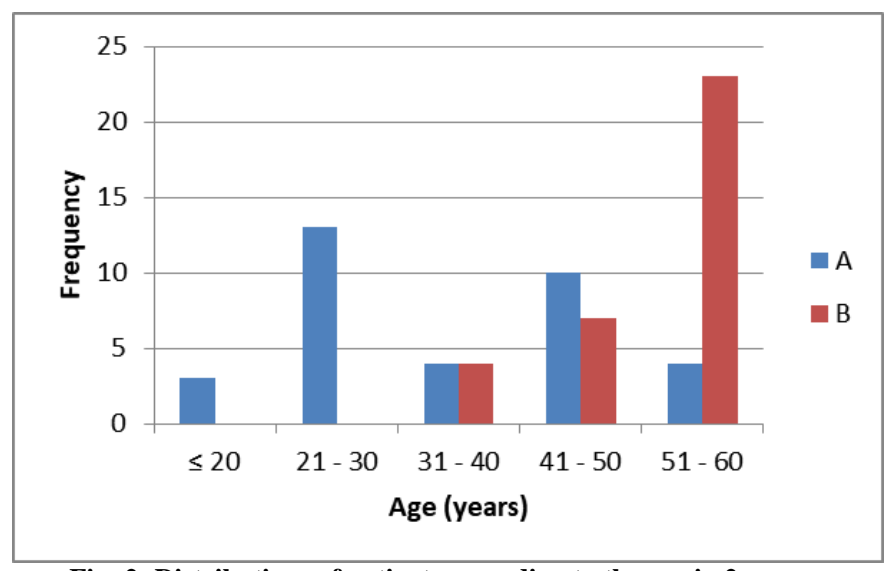

Fig- 2: Distributions of patients according to the age in 2 groups 
Right sided hernias were more common than the left side as depicted in Table 3. Forty-seven patients had a right sided hernia while twenty-one patients had a left sided hernia. Figure 3 depicts the distribution of patients according to the side of hernia in the two groups.

Table 3: Distribution of patients according to the side of hernia

\begin{tabular}{|l|l|l|l|l|l|}
\hline \multirow{2}{*}{ Side of Hernia } & \multicolumn{2}{|c|}{ Day Care Surgery } & \multicolumn{2}{l|}{ Routine Care Surgery } & \multirow{2}{*}{ p-value } \\
\cline { 2 - 5 } & n & \% & n & \% & \\
\hline Right inguinal hernia & 22 & $64.71 \%$ & 25 & $73.53 \%$ & \multirow{2}{*}{0.216} \\
\hline Left inguinal hernia & 12 & $35.29 \%$ & 9 & $26.47 \%$ & \\
\hline TOTAL & 34 & $100.00 \%$ & 34 & $100.00 \%$ & \\
\hline
\end{tabular}

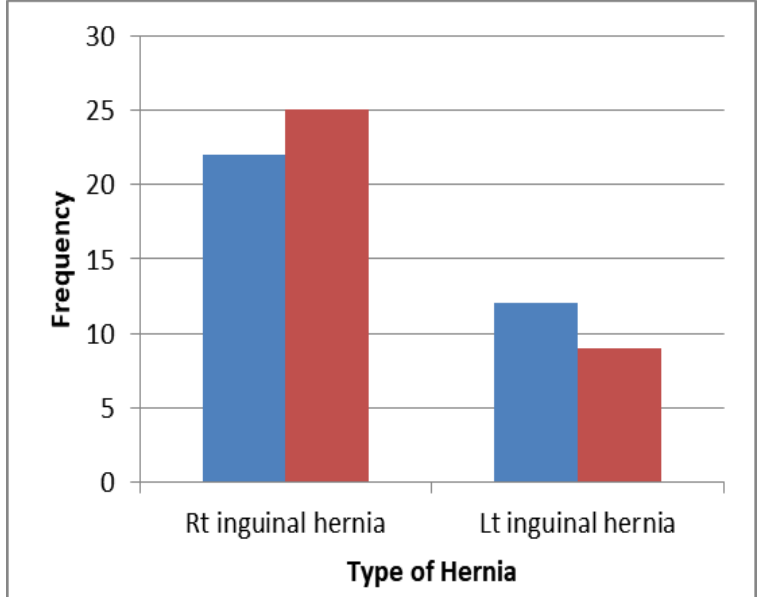

Fig- 3: Distribution of patients according to the side of inguinal hernia

The duration of hospital stay in hours was noted for all patients. The mean duration of hospital stay was found to be $8.71( \pm 1.03)$ hours and $44.47( \pm 13.06)$ hours in the day care surgery and routine care surgery group respectively as shown in table 4 and figure 4 . The duration of hospital stay was significantly shorter in the day care surgery group.

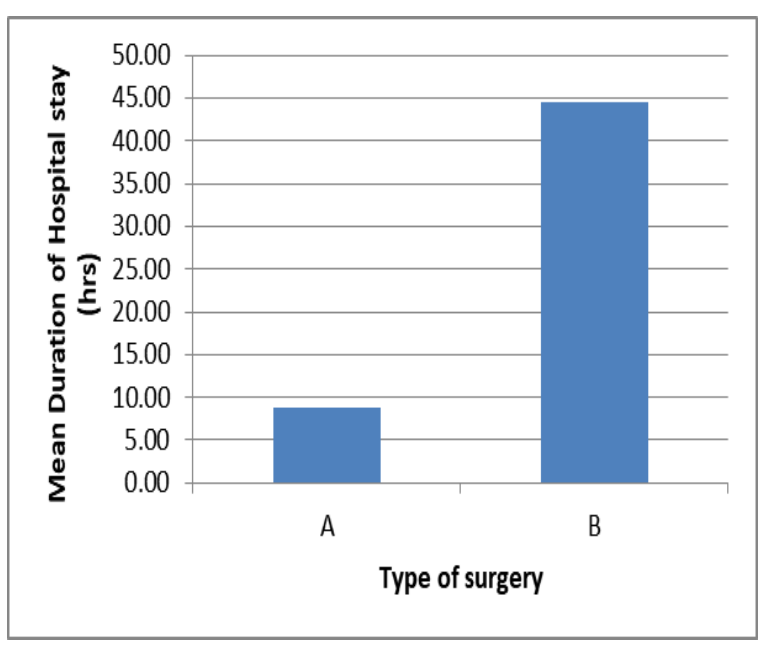

Fig- 4: Duration of hospital stay in the two groups
Table 4: Duration of hospital stay in the two groups

\begin{tabular}{|l|l|l|l|}
\hline $\begin{array}{l}\text { Duration of Hospital stay } \\
\text { (in hours) }\end{array}$ & $\begin{array}{l}\text { Day Care } \\
\text { Surgery }\end{array}$ & $\begin{array}{l}\text { Routine } \\
\text { Care } \\
\text { Surgery }\end{array}$ & p-value \\
\hline Mean & 8.71 & 44.47 & $<0.001$ \\
\hline \pm SD & \pm 1.03 & \pm 13.06 & \\
\hline
\end{tabular}

3 patients were readmitted within 7 days of discharge in the day care surgery group and 6 patients were readmitted in the routine care group in view of post-op complication. There was no significant difference in readmission rates between the two groups. Requirement of post-op analgesia was there in 22 patients where as in day care group the requirement of analgesia was seen in 11 patients. The following table and figure depicts the patients in 2 groups.

Table 5: Post-op readmission and analgesia requirement in the two groups

\begin{tabular}{|l|l|l|l|l|l|}
\hline \multirow{2}{*}{} & \multicolumn{2}{|l|}{$\begin{array}{l}\text { Day Care } \\
\text { Surgery }\end{array}$} & \multicolumn{2}{l|}{$\begin{array}{l}\text { Routine Care } \\
\text { Surgery }\end{array}$} & $\begin{array}{l}\text { p- } \\
\text { value }\end{array}$ \\
\cline { 2 - 5 } & n & \% & n & \% & \\
\hline Readmission in 7 days & 3 & $8.82 \%$ & 6 & $17.65 \%$ & 0.142 \\
\hline Post-op analgesia & 11 & $32.35 \%$ & 22 & $64.71 \%$ & 0.004 \\
\hline
\end{tabular}

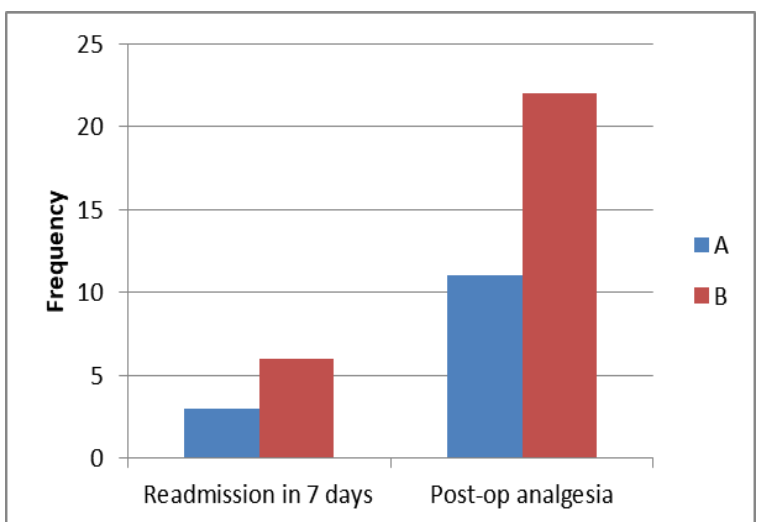

Table 5: Post-op readmission and analgesia requirement in the two groups

Table 6 and figure 6 depicts the distribution of post-op complications in the two groups in the form of bleeding, PONV, retention of urine, infection, and seroma formation at post-op day 3 and 7 . 


Table 6: Distribution of patient in the two groups according to the post-op complication
\begin{tabular}{|l|l|l|l|l|l|}
\hline \multirow{2}{*}{ Post op complications } & Day Care Surgery & \multicolumn{2}{|c|}{ Routine Care Surgery } & p-value \\
\cline { 2 - 6 } & n & $\%$ & n & $\%$ & \\
\hline Nil & 28 & $82.35 \%$ & 8 & $23.53 \%$ & $<0.001$ \\
\hline Bleeding & 1 & $2.94 \%$ & 0 & $0.00 \%$ & 0.157 \\
\hline PONV & 1 & $2.94 \%$ & 10 & $29.41 \%$ & 0.002 \\
\hline Retention of Urine & 0 & $0.00 \%$ & 12 & $35.29 \%$ & $<0.001$ \\
\hline Seroma at POD-3 & 4 & $11.76 \%$ & 4 & $11.76 \%$ & 0.500 \\
\hline Seroma at POD-7 & 0 & $0.00 \%$ & 0 & $0.00 \%$ & - \\
\hline TOTAL & 34 & $100.00 \%$ & 34 & $100.00 \%$ & \\
\hline
\end{tabular}

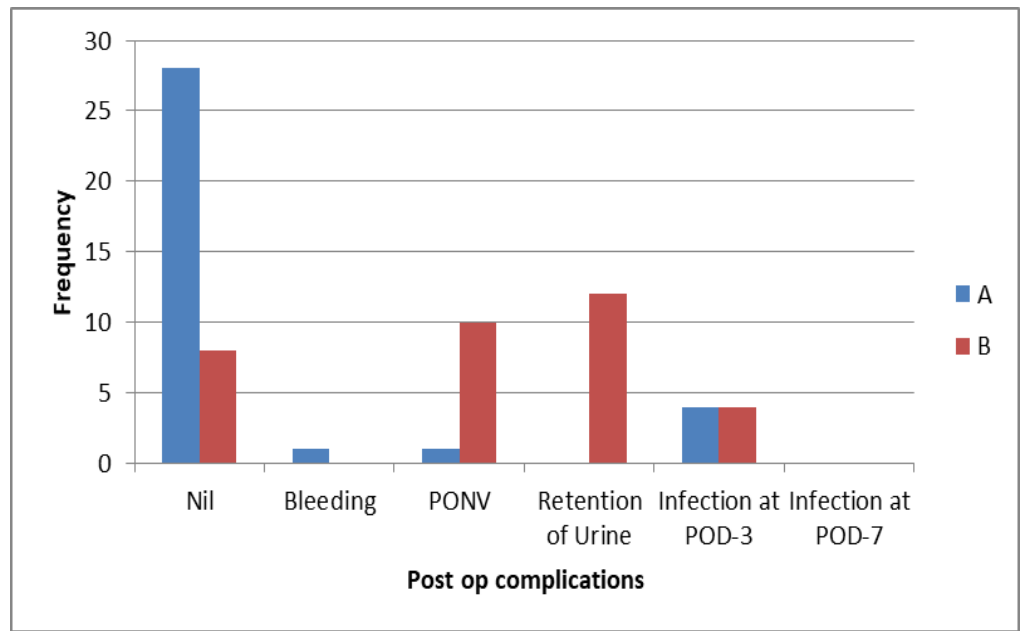

Fig- 6: Distribution of patient in the two groups according to the post-op complication

Table 7 depicts the duration to ambulation after surgery in hours. The time taken by the patient to ambulate after surgery was significantly less in the day care surgery group.

Table 7: Time for ambulation (in hours) after surgery in the two groups.

\begin{tabular}{|l|l|l|l|}
\hline & $\begin{array}{l}\text { Day } \\
\text { Care } \\
\text { Surg } \\
\text { Duration between surgery and } \\
\text { ambulation (in hours) }\end{array}$ & $\begin{array}{l}\text { Routi } \\
\text { ne } \\
\text { Care } \\
\text { Surg } \\
\text { ery }\end{array}$ & $\begin{array}{l}\text { p- } \\
\text { valu } \\
\text { e }\end{array}$ \\
\hline $\begin{array}{l}\text { Mean } \\
\pm \text { SD }\end{array}$ & 3.71 & 24.12 & $<0.0$ \\
\pm 0.76 & \pm 2.31 & 01 \\
\hline
\end{tabular}

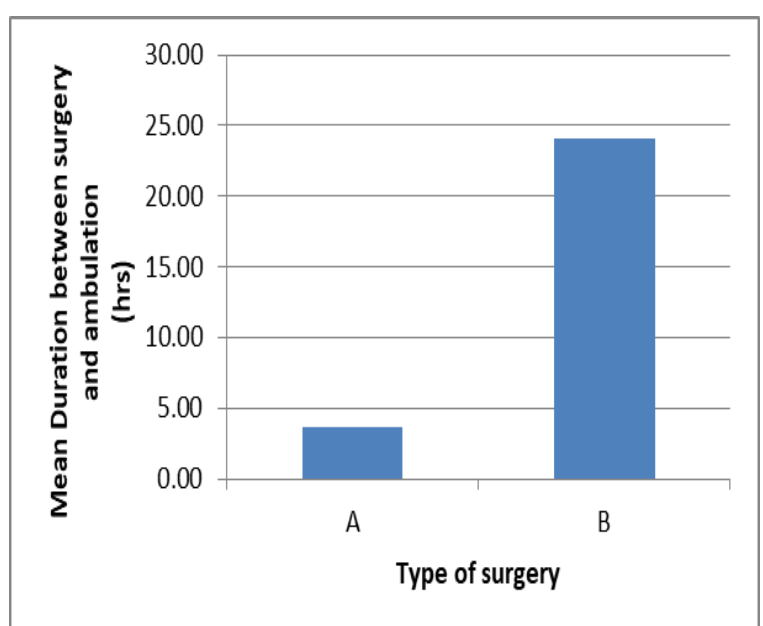

Fig- 7: comparison of time for ambulation (in hours) after surgery in the two groups.
The number of patients satisfied by the day care procedure is shown in table 6 . Of the 34 patients in the day care surgery group, 25 patients would opt for the procedure again if hernia develops on the other side while 26 patients would recommend the procedure to relatives or friends.

Table-6: number of patients satisfied by the procedure in day care group.

\begin{tabular}{|l|l|l|}
\hline Satisfaction and acceptance of procedure & \multicolumn{2}{|l|}{$\begin{array}{l}\text { Day Care } \\
\text { Surgery }\end{array}$} \\
\cline { 2 - 3 } & n & \% \\
\hline Will opt for day care surgery if it develops on & 2 & 73.53 \\
other side & 5 & $\%$ \\
\hline Will recommend to others & 2 & 76.47 \\
& 6 & $\%$ \\
\hline
\end{tabular}

\section{DISCUSSION}

Inguinal hernia is a common presentation in the outpatient clinic. Predisposing factors in the elderly patients include smoking, connective tissue disorder, chronic straining, and previous lower abdominal surgery. Young patients usually have a congenital hernia. Surgery is the only curative treatment for this condition. Various techniques of repair are in use utilizing prosthesis or pure tissue repair. 
Shouldice and Desarda technique are tissue repair while Lichtenstein tension free repair utilizes a mesh. ${ }^{[6,7]}$ The Lichtenstein repair is a commonly performed procedure which can be done under local anesthesia and has a recurrence rate of less than one percent. ${ }^{[8,9]}$

Day care surgery is a fast growing concept for short duration surgical procedures. Many third world countries now have a separate day care centre where patients are selected as per laid protocols. The patient is admitted on the day of surgery and discharged by evening. There are many advantages of day care surgery like short hospital stay, early ambulation, recovery in home environment, less PONV, and use of local anesthesia. However, it is very challenging at the same time, especially in a country like ours with a large number of patients waiting for hernia repair. Day care procedures require a team of surgeon, anesthetists, and nursing staff working together in a dedicated day care unit at the hospital. Day care surgery can help reduce the burden over the hospital by reducing the number of patient in the waitlist and simultaneously provide an opportunity for other major surgeries to be performed. Thorough patient counseling is a very important aspect of day care procedures in our country. The belief that patients will get better care if kept admitted in hospital till removal of sutures prevents them from opting for day care surgery. However, the risk of nosocomial infection in routine admission is something that the patient is unaware of. In India, there has been a gradual rise in the number of dedicated day care centers in metropolitan cities who perform day care procedures exclusively. Similarly, the anesthetic techniques need to be improvised for success of day care surgery. In 1984, the Society of Ambulatory Anesthesia (SAMBA) was developed with focus on using techniques for day care procedure. ${ }^{[10]}$

In our study, 34 patients were operated using the Lichtenstein tension free approach under local anesthesia in the day care group (Group A). Similarly, 34 patients were operated using the same technique in the routine care group (Group B) under local/spinal/general anesthesia.

The mean age of patient in group A was $35.5( \pm 12.06)$ years whereas the mean age in group B was $51.18( \pm 6.69)$ years. More number of elderly patients preferred the routine care surgery under general/spinal anesthesia over day care surgery in local anesthesia.

It was observed that all the patient in our study were male similar to the study done by Kark et al in 1998. ${ }^{[11]}$ This could be because the female patients were not satisfying the inclusion criteria of this study besides an already low incidence of female inguinal hernia. Right sided inguinal hernia was common than the left sided hernia in our study. In group A, $64.71 \%$ and in group $\mathrm{B}, 73.53 \%$ had right sided inguinal hernia. O'Dwyer et al (2002) in his study observed male right sided predominance due to the late descent of right testis and high incidence of patent processus vaginalis on the right side. ${ }^{[1,12]}$

The mean duration of hospital stay in group A patient was $8.71( \pm 1.03)$ hours whereas in group B was $44.47( \pm 13.06)$ hours. The duration of hospital stay was significantly lower in the day care group compared to routine care group $(\mathrm{p}<0.05)$.

Post-op analgesia requirement was more in group B patients $(84.71 \%$ versus $32.35 \%$ ). Three patients from group A were readmitted within 7 days after discharge because of complications like unbearable pain and PONV. $82.35 \%(n=28)$ patients in group $\mathrm{A}$ had no complications and experienced a comfortable post-op recovery whereas only $23.53 \%(n=8)$ in group B had a smooth post-op recovery. $29.41 \%(\mathrm{n}=10)$ patients had PONV and $35.29 \% \quad(n=12)$ patients developed urinary retention during recovery. 10 patients, all of which were operated using spinal anesthesia needed one time catheterization in view of urinary retention while two patients were discharged with urinary catheter in-situ. There was no incidence of infective complication, however seroma was noted in 
$11 \% \quad(\mathrm{n}=4)$ patients on POD3 which resolved on its own by conservative methods.

Another statistically significant finding $(\mathrm{p}<0.05)$ was that patient in group A were ambulatory in $3.71( \pm 0.76)$ hours which less compared to those in group B who were ambulatory in $24( \pm 2.31)$ hours.

All the patients in group A were asked if they develop hernia on the other side would they prefer day care surgery and would they recommend day care surgery to their relatives or friends. $73.53 \% \quad(n=25)$ patients would again opt for day care surgery while $76.47 \% \quad(n=26)$ patients felt they would recommend day care surgery to others. Most of the patients in group A were thus satisfied with the procedure.

One of the pitfalls of this study is that only patients who were literate or had a literate attendant with them, residing within a ten kilometer radius of the hospital, and an active means of communicating with the hospital in case of emergency, could be considered for the day care procedure. Only uncomplicated hernia patients could be taken up for the study and the choice of anesthesia in the routine care group was left over the anesthetist, were the other pitfalls in the study. ${ }^{[13]}$

\section{CONCLUSION}

With this study we conclude that day care surgery for hernia using Lichtenstein's tension free repair under local anesthesia is a feasible option even in a public tertiary care center if patient selection and procedure is planned judiciously in consultation with the anesthetist. The benefit of newer drugs and advanced technology can be extended to the patient. Day care surgery can also help to reduce the number of patients in the waiting list of the hospital. It has the benefit of significantly shorter hospital stay, early ambulation, less PONV, less analgesic requirement, and recovery in comfortable home surrounding along with the feasibility of work from home. With little effort day care surgery can be started in public health care setup with good outcome.

Acknowledgement: None

\section{Conflict of Interest: None}

\section{Source of Funding: None}

Ethical Approval: Approved

\section{REFERENCES}

1. Pradeep Goyal, Shiv Kumar Sharma , Kamaljeet Singh Jaswal, Sandeep Goyal , Mushtaq Ahmed, Gauravrai Sharma, Poonam Pandotra.. Comparison of inguinal hernia repair under local anesthesia versus spinal anesthesia. iosr-jdms (Jan 2014); pp54-59

2. Amato, B., Compagna, R., Della Corte, G.A. et al. Feasibility of inguinal hernioplasty under local anaesthesia in elderly patients. BMC Surg 12, S2 (2012). https://doi.org/10.1186/1471-248212-S1-S2

3. Louis Anthony O. Delos Reyes, M.D.; Axel L. Elises, M.D., F.P.C.S.; Daniel R. Albaño, M.D. and Fidelis Espiritu-Quiza, M.D., F.P.C.P.. Local Versus Spinal Anesthesia in Lichtenstein Mesh Technique for Inguinal Hernia Repair in Ambulatory Patients: A Randomized Controlled Trial. PJSS 2011; 66(3)

4. Jeetendar Paryani, Gunvant H. Rathod, Rakesh A. Makwana, Ravi P. Gadani, Rajesh K. Patel, Routinevs Day-Care Surgery in Case of Unilateral Inguinal Hernia in Public Hospital Setting, International Journal of Surgical Research, Vol. 2 No. 4, 2013, pp. 37-41. doi: 10.5923/j.surgery.20130204.03

5. J. Antonio Aldrete. Discharge criteria. Baillieres Clinical Anaesthesiology 1994; 8(4): https://doi.org/10.1016/S09503501(05)80109-6.

6. Chan CK, Chan G. The Shouldice technique for the treatment of inguinal hernia. J Minim Access Surg. 2006;2(3):124-128. doi:10.4103/0972-9941.27723

7. Gurgenidze M, Datuashvili G. Desarda Technique For Inguinal Hernia Repair. Georgian Med News. 2018 Jul-Aug;(280281):7-10. PMID: 30204086. 
8. Devesh Bhomia , Neha Bhomia and Pankaj Jain. Prospective Significance Of Local Anesthesia For Lichenstien Tension Free Mesh Hernioplasty Compared To Regional Anesthesia. International Journal of Current Advanced Research 2018; 7(3):DOI: http://dx.doi.org/10.24327/ijcar

9. Metzger J, Lutz N, Laidlaw I; Guidelines for inguinal hernia repair in everyday practice; Ann R Coll Surg Engl 2001; 83: 209-214

10. Fong, R., Sweitzer, B.J. Preoperative Optimization of Patients Undergoing Ambulatory Surgery. Curr Anesthesiol Rep 4, 303-315 (2014). https://doi.org/10.1007/s40140-014-0082-5

11. Kark AE, Kurzer MN, Belsham PA. Three thousand one hundred seventy five primary inguinal hernia repairs; advantages of ambulatory open mesh repair using local anaesthesia. Am J Coll Surg 1998;186: 1541-7

12. O’Dwyer PJ, Serpell MG, Millar K, Paterson C, Young DV, Hair A, et al. Local or general anaesthesia for open tension-free hernioplasty: A randomized trial. Ann Surg 2002; 237: 574-9

13. Dr Suresh Patil, Dr Amey Talpallikar, Dr Kiran Chayagol, Kushagar Garg. Uncomplicated Inguinal Hernia - A Day Care Procedure. Sch. J. App. Med. Sci., 2017; 5(7E):2898-2914. DOI: $10.21276 /$ sjams

How to cite this article: Kumar A, Poddar D, C Raja Bhanu Kiran et.al. A comparative study between day care and routine care inguinal hernia mesh repair. International Journal of Research and Review. 2021; 8(6): 140-147. DOI: https://doi.org/10.52403/ijrr.20210617 